\title{
POR QUEM DOBRAM OS SINOS? REFLEXÕES SOBRE NEOCONSTITUCIONALISMO E CIÊNCIA JURÍDICA ${ }^{1 *}$
}

\author{
FOR WHOM THE BELL RINGS. CONSIDERATIONS ON \\ NEOCONTITUCIONALISM AND JURISPRUDENCE
}

\author{
Alfonso de JULIOS-CAMPUZANO**
}

\section{RESUMO:}

O século XX acarretou transformações decisivas do Estado de Direito que levam ao início de uma nova fase no desenvolvimento do constitucionalismo. Este trabalho pretende oferecer uma aproximação com o Estado Constitucional de Direito, que veio a superar o Estado Legislativo de Direito, formado sob aos auspícios do positivismo legalista. A irrupção do constitucionalismo contemporâneo - que implica a consagração definitiva da supremacia da Constituição como verdadeira norma jurídica - no entanto, exige desafios importantes que se relacionam, diretamente, com a nova era da interdependência e a crescente perda do protagonismo do Estado-Nação. Isso comporta a necessidade de superar a velha dogmática jurídica estatalista para transcender os constritos limites espaciais do modelo estatal e promover garantias jurídicas que assegurem a efetividades dos direitos fundamentais

\section{PALAVRAS-CHAVE:}

Constitucionalismo; Estado de Direito; Estado-Nação; transformação.

\begin{abstract}
:
20th Century has provided weighty changes that entails the beginning of a new period in the development of constitutionalism. This paper aims to offer an approach to constitutional State that has overcome legislative State forged under the domains of legalist positivism. However, the appearance of current constitutionalism -involving the definitive consecration of constitution`s supremacy as a real legal norm-, implies important challenges regarding the State-nation weakness in an interdependence and globalization age. This includes the need to overcome the old dogmatic legal state in order to transcend the constrained geographical limits of the state model and provide legal guarantees to ensure the realization of rights.
\end{abstract}

\footnotetext{
* Tradução com alterações - autorizadas pelo professor espanhol citado acima. Traduzido por Prof ${ }^{\mathrm{a}}$. Dr ${ }^{\mathrm{a}}$. Valéria Ribas do Nascimento: Professora Adjunta do Departamento de Direito da Universidade Federal de Santa Maria (UFSM).

** Professor Titular de Filosofia do Direito na Universidade de Sevilha (Espanha), com períodos de pesquisa em diversas instituições, como por exemplo: Universidade de Ferrara (Itália), na Universidade de "Oxford", "London School of Economics and Political Science", Universidade Federal de Santa Catarina, da qual é também professor convidado do curso de Direito, na Universidade Federal do Paraná, na UNIPAR (Universidade Paranaense) e na Unisinos (Sevilha/Espanha). E-mail: julios@us.es
} 
KEYWORDS:

Constitutionalism; Rule of Law; State-Nation; changes.

\section{INTRODUÇÃO: $\quad$ POSITIVISMO LEGALISTA, ESTADO DE DIREITO E CONSTITUIÇÃO}

Depois do desastre totalitarista do século passado, o pensamento jurídico europeo, profundamente afetado por tão abominável disputa e por episódios dramáticos de negação dos direitos humanos, sentiu a necessidade de mexer nas entranhas do velho e injuriado direito natural, para superar o pesadelo de um formalismo jurídico que propiciou a identificação estreita entre validade e justiça, mediante a redução do universo da juridicidade ao direito positivo. Após o apogeu do positivismo legalista, a exaltação cientificista do Direito como um objeto axiologicamente neutro, fazia-se necessário restabelecer a ligação preconizada pelo jusnaturalismo racionalista, inserindo o direito no horizonte da justiça, da liberdade, da igualdade e da dignidade humana, valores vinculados diretamente com os direitos humanos, cujas primeiras declarações promulgaram-se no ambiente cultural da ilustração.

Esse contexto cultural compõe as bases teóricas do Estado de Direito, através de sucessivas contribuições que consolidariam a limitação do poder do Estado, a consagração do princípio da soberania popular, a regra da maioria e a eleição dos governantes mediante um sistema de democracia representativa, a separação de poderes, a garantia dos direitos civis e políticos, o princípio da legalidade e a segurança jurídica. Ainda, o Estado de Direito, como construção teórica foi iluminado pela ciência alemã do direito público, sob a perspectiva do positivismo jurídico que dominava a Europa do século XIX - especialmente depois das contribuições de Von Habitem e Von Mohl que foram os pais da fórmula Rechsstaat -, seus principais fundamentos teóricos possuem suas raízes no jusnaturalismo racionalista, no contratualismo, na tradição liberal-democrática e nas decisivas contribuições que a Ilustração legou à humanidade. É sabido, no entanto, que o Estado liberal de Direito representou as aspirações políticas da burguesia, que buscava consolidar em nível político o poder que já ostentava em outras esferas da vida, servindo-se para isso de algumas diretrizes, que seguem a seguir:

a) em nível político, da ideologia liberal que, sutilmente manipulada pela nova classe social emergente, perdeu sua marca emancipatória e revolucionária para vincular-se aos interesses econômicos, como o liberalismo arraigado e decadente ${ }^{2}$;

R. Fac. Dir. UFG, v. 40, n.1, p. 32 - 53, jan./jun. 2016

ISSN 0101-7187 
b) no âmbito jurídico, do positivismo legalista, que levou ao abandono dos conteúdos jusnaturalistas de tradição liberal contratualista, incluindo o monopólio da produção jurídica por parte do aparato estatal e a consagração do princípio da legalidade, da onipotência da lei e da primazia do poder legislativo;

c) ainda, pode-se citar a identificação entre justiça e validade em função da qual, todo direito válido, era por si mesmo legítimo.

Esta concepção puramente formal da democracia e dos direitos se sustentou nas construções teóricas da ciência jurídica do positivismo legalista através das contribuições dos principias líderes da ciência alemã do Direito Público, dentre eles, cita-se: Gerber, Thoma, Laband e Jellinek. Os mesmos elaboraram uma sólida rede conceitual e um arsenal de categorias jurídicas que consagraram uma concepção estritamente descritiva da ciência do Direito, defendendo a neutralidade cientifica e a purificação total dos juristas, manifestada através da exclusão de toda sorte de valoração vinculada ao seu objeto de conhecimento.

Uma ciência jurídica descritiva, alheia a juízos de valor sobre o direito e sobre seus conteúdos substantivos de justiça, veio assim a brindar definitivamente esse novo paradigma jurídico do Estado de Direito frente à tosca e vã pretensão de contaminar o Direito com exigências axiológicas externas ao próprio sistema jurídico, processo que culminaria com a assimilação dos direitos fundamentais, como categorias estritamente formais através de sua identificação com os direitos públicos subjetivos. Em suma, o abandono do jusnaturalismo pela irrupção do paradigma cientificista do direito constituiu um hiato decisivo na configuração dessa nova ordem jurídica.

O trabalho da dogmática jurídica estava diretamente associado à exegese legal, conforme os postulados essenciais de uma ontologia jurídica positivista, em função da qual somente se considerava direito, o direito promulgado pelo Estado. Os princípios da unicidade, estatalidade e racionalidade conformavam, assim, ao tripé ideológico sobre o qual descansava a ciência do Direito.

Dessa identificação estreita entre unicidade, estatalidade e racionalidade seria fácil concluir pela ligação com um quarto princípio, o da legitimidade, que permitiria postular, segundo um raciocínio dotado de inequívoca matriz tautológica, que a legitimidade não procederia de nenhum fator metajurídico, pois somente é legítimo o direito do Estado, por ser o único direito, estatal e racional ${ }^{3}$.

A Constituição se colocava, assim, como um marco de referência cuja continuidade e eventual modificação ficaria, em todo caso, submetida ao arbítrio do 


\section{POR QUEM DOBRAM OS SINOS? [...]}

legislador. Ademais, a Constituição foi concebida como um marco jurídico eminentemente procedimental, orientada ao estabelecimento de regras de organização do poder, cuja virtualidade se envolveria, essencialmente, com a criação de uma ordem institucional para a organização do Estado, a distribuição de competências entre os diferentes poderes e ao estabelecimento de normas de produção jurídica, cuja validade estaria delimitada por parâmetros formais de competência e procedimento que determinariam a adequação constitucional das normas vigentes.

O Estado liberal de Direito edificou-se, portanto, sobre um modelo constitucional flexível, facilmente modificável pelo legislador, já que a Constituição não foi considerada inicialmente- como uma categoria supralegal, mas sim permaneceu como norma primeira do ordenamento, submetida à vontade do legislador, cuja atuação foi disciplinada somente pelo aspecto formal. Foi o legislador quem, em última instância decidiu sobre a modificação da Constituição que, por sua vez, estava revestida sob a forma de uma simples lei, desprovida de mecanismos especiais de proteção que dificultem sua reforma.

Dessa forma, as Constituições do século XIX expressavam uma determinada cultura jurídica e política que derivava, diretamente, do legado cultural da Revolução Francesa e dos pressupostos de racionalidade, ordem e sistematicidade que, iluminados pelo jusnaturalismo racionalista, constituíram a base sobre a qual se edificaria o corpo teórico do positivismo legalista.

O Estado de Direito trouxe, nesse sentido, uma inovação sem precedentes, ao substituir o governo dos homens pelo governo das leis e estabelecer limites, que, em seu exercício, o poder não poderia vulnerar. Frente ao poder arbitrário do Ancien Régime, o constitucionalismo estabeleceu a submissão do governante ao princípio da legalidade.

Sendo assim, esse Estado de Direito que se submetia ao princípio da legalidade seria, ao mesmo tempo, um Estado precário de Direito, na medida em que registrava carências que demonstravam a insuficiência do modelo teórico sobre o qual o mesmo se sustentou. Em primeiro lugar, produziu-se uma identificação - já mencionada - entre legalidade e legitimidade que foi consequência da redução de todo o direito ao direito do Estado que, por razão de sua origem, pressupunha-se legítimo. Em segundo lugar, o modelo teórico do positivismo legalista, baseava-se sobre a sacralização da lei que se convertia, por meio de sua indeclinabilidade normativa, no grande tótem da nova cultura jurídica.

$\mathrm{Na}$ concepção do positivismo legalista a exclusividade da produção jurídica foi transferida ao Estado que, ao proclamar o monopólio de todo o direito, conferiu a lei à 
Alfonso de Julios-Campuzano e Valéria Ribas do Nascimento

categoria de fonte do direito por excelência, dotada de força absoluta sobre qualquer outra normatividade. E a Constituição não fez, senão, ratificar esta concepção teórica subjacente sobre a qual descansava toda a ordem jurídica. O constitucionalismo do positivismo oitocentista foi considerado como um constitucionalismo frágil que se limitou a estabelecer o esquema básico da ordem política e de suas instituições, atribuindo competências e determinando procedimentos, um constitucionalismo das regras do jogo, dos limites que não podem ser ultrapassados, dos direitos que não podem ser transgredidos, um constitucionalismo de mínimos que estabeleceu um marco de convivência baseado na autonomia dos indivíduos nas esferas social e política.

A efetividade da Constituição dependia do legislador. Portanto, pelo velho esquema do positivismo legalista, a Constituição não era uma verdadeira norma jurídica que vinculava a todos os cidadãos e que regia todos os âmbitos da vida social, mas sim, uma norma sui generis de alcance limitado, uma norma fundante da ordem jurídica, uma norma básica da ordem política. Uma norma carente, sem maiores pretensões que a de constituir, a de fundar, a ordem política sobre a qual repousava o sistema jurídico.

Desse modo, o constitucionalismo acabou transformando-se em legalismo ${ }^{4}$ : sua força normativa estava irremediavelmente condenada a supremacia da lei, a onipotência do legislador e a eficácia mediata de seus conteúdos. A Constituição foi subjugada a uma particular condição normativa, como norma de direito público de caráter supralegal, ou seja, estaria sobre a lei, mas não seria a e lei, vincularia o legislador, mas somente a este caberia a responsabilidade em desenvolver as prescrições normativas estabelecidas na Constituição.

Dessa concepção do direito, depreendeu-se um constitucionalismo inevitavelmente frágil, porque a Constituição estaria aprisionada pela vontade majoritária que era representada pelo poder legislativo; e isso comportaria, também, um constitucionalismo insuficiente, em que primavam, principalmente, os elementos estritamente formais da ordem política, subordinados a hegemonia da lei como pedra angular da ordem jurídica. Ao atribuir ao legislador a condição de protagonista da produção normativa associada à mistificação da lei, o paradigma do positivismo legalista se mostrou resistente em oferecer qualquer outro tipo de aparato aos operadores jurídicos. A função judiciária reduziu-se a um trabalho estritamente mecânico de acompanhamento processual de materialização social das normas jurídicas.

A aplicação das normas foi concebida como um processo mecânico de subsunção, mediante o qual se ofereceria, em um caso concreto, a consequência jurídica 


\section{POR QUEM DOBRAM OS SINOS? [...]}

prevista na norma, sem que houvesse espaço para a discricionariedade judiciária. Fechada a porta da interpretação - in claris non fit interpretatio-, a função do juiz limitava-se a um procedimento lógico-dedutivo, no qual a partir de uma premissa maior, e mediante o estabelecimento de uma premissa menor, haveria de chegar-se a uma conclusão. A subsunção é, assim, outra cara do positivismo legalista. Faz-se necessário sublinhar, portanto, que a adesão expressa da doutrina da separação de poderes é característica distintiva de toda esta concepção jurídica, a qual implica uma clara separação das funções judiciária e legislativa, de modo que o trabalho judicial fica limitado a explorar a vontade do legislador. Por outro lado, a concepção de lei como expressão da vontade dos legisladores históricos confere ao trabalho interpretativo um alcance limitado e complementar, consistente em descobrir o sentido prévio e acabado da vontade do que legislou (TARELLO, 1995, pp. 75-77).

O incerto caminho dos acontecimentos históricos, no entanto, não tardaria em evidenciar as grandes carências do positivismo legalista e de seu modelo constitucionalista frágil. A precariedade deste paradigma constitucional mostrou-se com evidencia diante o descrédito do Estado mínimo e de sua escandalosa redução formalista dos diretos que, a partir de uma odiosa concepção abstrata do indivíduo, terminou por negar as exigências elementares de justiça que se abriram décadas mais tarde, sob a forma de direitos sociais. De outro lado, o lamentável episódio de totalitarismos do século XX, veio a confirmar o escandaloso fracasso das brilhantes construções teóricas da dogmática jurídica (DE VEGA, 2009, p. 4). Esses mencionados fracassos, levaram ao surgimento do constitucionalismo contemporâneo.

\section{AS RAÍZES DO CONSTITUCIONALISMO CONTEMPORÂNEO}

O constitucionalismo contemporâneo surgiu como fruto da convergência entre duas tradições constitucionais diferentes que formavam as bases do Estado Constitucional, modelo que se afirma com características próprias e que se concretiza com Constituições fortemente normativas dotadas de um amplo sistema de garantias. As Constituições contemporâneas deixaram de ser normas sucintas, para incorporar um amplo conteúdo substancial, que aponta para um ambicioso programa de reforma social. E são, por outro lado, Constituições rígidas, vedadas ao insaciável expansionismo do legislador, que teve de adequar suas funções aos princípios e diretrizes constitucionais, sob o olhar fiscalizador dos juízes.

Em oposição às Constituições do século XIX, que tomam a sociedade como um dado a priori, as Constituições passam a estabelecer um sólido caráter normativo, na medida R. Fac. Dir. UFG, v. 40, n.1, p. 32 - 53, jan./jun. 2016 
Alfonso de Julios-Campuzano e Valéria Ribas do Nascimento

em que se erigem como um modelo de transformação social. A Constituição se converte assim na referência central de um projeto coletivo de ação política que aspira reger efetivamente a atuação dos poderes do Estado, com objetivo de ordenar a materialização social dos fins contidos na Carta Maior.

Desse modo, a Constituição assume uma função eminentemente diretiva que se condensa em um catálogo de direitos e em uma articulação de corte marcadamente teleológico, o qual pretende ordenar o curso da vida social e política conforme os preceitos que nela estão contidos. O constitucionalismo forjado sob os auspícios da tradição revolucionária francesa apresenta uma dimensão contratualista que, diferentemente, do constitucionalismo britânico, perde seu estilo individualista para expressar-se, sobretudo, como totalidade que personifica um projeto coletivo ${ }^{5}$

Neste modelo, as Constituições buscam regular a realidade social, pois parte-se de uma rejeição efetiva do statu quo político-social, rechaço que é, precisamente, a base do fenômeno revolucionário que propicia o nascimento da Constituição. Essa é a dimensão essencialmente revolucionária do poder constituinte como um poder continuamente atuante que, baseado em uma concepção rousseuniana da vontade geral, propicia que o texto constitucional fique aberto, portanto, à causalidade das alterações políticas, das preferências e interesses dos grupos majoritários. A tensão entre Estado de direito e democracia se resolve, neste caso, a favor da segunda ao outorgar a maioria, um poder onipotente, que prevalece com frequência sobre o próprio texto constitucional. Aqui reside precisamente a principal fragilidade do constitucionalismo que surge da Revolução Francesa, já que, ao basear-se em uma concepção majoritária de democracia, esta se constitui em uma força motriz do poder constituinte que se projeta dinamicamente até o futuro (FIORAVANTI, 2007, p. 64).

Esse permanente revisionismo termina por esgotar o espaço vital dos poderes constituídos ${ }^{6}$. A concepção revolucionária francesa debilita, dessa forma, o conceito de limite que norteia o Estado de Direito, concedendo o protagonismo decisivo ao elemento democrático representado pela vontade majoritária, o qual se traduz, em nível jurídico, em uma onipotência do legislador como representante da vontade majoritária. A lei converte-se, assim, em elemento central da produção jurídica e o legislador é elevado à categoria de artífice da nova ordem.

$\mathrm{Na}$ tradição francesa, assim, a Constituição desempenha uma função essencialmente política e suas cláusulas ficam submetidas à mediação da lei, de modo que através desta, evidencia-se a plenitude normativa do ordenamento jurídico. A lei é a principal 


\section{POR QUEM DOBRAM OS SINOS? [...]}

protagonista e a verdadeira autora da ordem jurídica, a qual se subordina a própria Constituição. A tradição constitucional francesa passa, desse modo, para uma concepção acentuadamente legalista ${ }^{7}$.

O constitucionalismo norteamericano, por outro lado, põe em evidência a garantia dos limites ao poder, renunciando abertamente a um modelo programático de Constituição e a dimensão normativa ou dirigente característica das constituições derivadas da Revolução francesa, para primar à dimensão limitadora da Constituição. Frente ao poder constituinte francês, que nasce para abolir o Antigo Regime e para modelar, em oposição, uma nova sociedade concorde com os valores que propugna a ideologia revolucionária-liberté, egalité, fraternité -, o poder norteamericano não aspira produzir alterações na ordem social, mas sim, estabelecer uma nova ordem política. Esta é, na posição de Fioravanti, a raiz da diferença entre as duas tradições: o constitucionalismo francês se constroi na relação de permanente oposição com o antigo regime, ao qual pretende substituir por uma nova ordem social e política que responda a determinados valores preteridos pela sociedade estamental e o sistema de privilégios que a ela é inerente. A luta pelos direitos está associada, portanto, a luta contra a ignomínia e a injustiça, a ruptura definitiva com a velha ordem estamental e a superação dos vínculos corporativos que identificam o mandamento imperativo para construir uma nova ordem social. A Constituição representa, assim, um novo contrato social pelo qual os indivíduos adquirem a condição de cidadãos formalmente iguais e convencionam a criação de uma nova ordem, baseada em alguns pressupostos: a) nos pilares da vontade majoritária, $b$ ) no domínio ou supremacia do legislador como expressão da unidade do povo e $c$ ) no domínio da lei geral e abstrata como primordial fonte do direito.

A revolução norteamericana responde, também, a uma ruptura com a metrópole e a submissão a coroa britânica - e evoca um pacto social pelo qual se cria uma nova ordem política, mas aqui não é necessário abolir um antigo regime com pesadas cargas de injustiças e discriminações. Não se pode esquecer; no entanto, que a revolução norteamericana desencadeou um movimento emancipador vigoroso que se traduziria em uma ordem social integralmente nova baseada na superação das injustiças do anterior regime colonial, mas, seja como for, aqui não existe a urgente necessidade de derrotar o tirano, de desfazer as injustiças, de abolir abusos e desmandos para criar, desde a sua própria base, uma nova ordem social concebida a partir de premissas e princípios completamente opostos aos anteriores.

O êxito da sociedade coletiva revolucionária francesa gira em torno da necessidade de um Estado forte que lute pela transformação. O componente essencial da 
Alfonso de Julios-Campuzano e Valéria Ribas do Nascimento

revolução norte-americana gira em torno da desconfiança frente ao legislador, cujo poder ilegítimo vai mais além de seus próprios confins em um afã inexoravelmente invasivo e expansionista. $\mathrm{O}$ núcleo do constitucionalismo americano baseia-se precisamente na suspeita contra ao poder legislativo e na necessidade de estabelecer limites efetivos, operativos e sólidos frente à irresistível tentação da tirania da maioria e sua insaciável voracidade ${ }^{8}$.

O constitucionalismo estadunidense gira sobre a supremacia da Constituição, cujo valor normativo deve ficar a salvo da tentação expansionista do poder legislativo. A Constituição é percebida como verdadeira norma jurídica e vértice do ordenamento. A Constituição norte-americana se constroi, assim, sobre duas ideias fundamentais: por um lado, o conceito de limite frente ao poder, que ocupa um lugar primordial na Carta Magna através da consagração dos direitos fundamentais e um sistema de equilíbrio de poderes - check and balances- que trata de debilitar sua eventual concentração. Esta acentuada dimensão limitadora do poder permitiu a autores como Mcllwain e Matteucci asseverar que o constitucionalismo norte-americano representa o constitucionalismo moderno, já que procura a limitação do poder através do direito ${ }^{9}$.

A dimensão garantista dessa tradição, por sua vez, concretiza-se na atribuição aos juízes do controle de constitucionalidade das leis, que tem sua origem na célebre sentença da Corte Suprema norte-americana, presidida pelo juiz Marshall, no caso Marbury vs. Madison de 1803. A partir desse momento, os juízes convertem-se nos autênticos guardiães da Constituição e assumem a missão, em primeiro lugar, de julgar a compatibilidade das normas jurídicas e, portanto, sua coerência relacionada a produção de normas contidas na Constituição, e, em segundo lugar, de definir mediante a interpretação o sentido genuíno das cláusulas constitucionais (JIMÉNEZ ASENSIO, 2005, pp. 99-100).

Dessa forma, no constitucionalismo norteamerico, a Carta Magna adquire a condição de verdadeira norma suprema do ordenamento, cujo protagonismo e centralidade como norma fundamental do ordenamento jurídico não são reduzidos por nenhuma outra fonte do direito. Ao instituir a Constituição como norma suprema garantida, desaparece a mediação da lei como veículo através da qual a Constituição se explicita no ordenamento e aquela se converte em uma fonte do direito subordinada a Constituição. No modelo constitucional norteamericano, o legislador não ostenta um poder integral e irreprimível, mas sim fica submetido à Constituição, sendo sua atividade controlada pelos juízes. À diferença do constitucionalismo de origem francesa, o poder constituinte opera somente no momento inicial para submeter-se, logo, aos mecanismos regulados dos poderes constituídos, de 


\section{POR QUEM DOBRAM OS SINOS? [...]}

maneira que a Constituição como norma fundamental adquire plenitude normativa uma vez promulgada. $\mathrm{O}$ momento constituinte não se projeta indefinidamente no tempo, recriando-se permanentemente através da atividade legislativa, mas sim aparece cronologicamente limitado. A Constituição se configura, então, como o conjunto de normas que assegura a convivência e o gozo da autonomia pessoal na nova ordem política cujas regras de organização institucional se encontram na norma fundamental. A tensão entre democracia majoritária e Estado de Direito resolve-se agora a favor deste último, que consegue impor sua lógica de limitação do poder frente à potencialmente opressora vontade majoritária. Afirmase, assim, a supremacia do direito sobre a política e se limita o poder do legislador que fica submetido à Constituição sob a atenta supervisão dos juízes. Desse modo, o constitucionalismo americano - que descansa sobre a ideia de supremacia constitucional e garantia jurisdicional - materializa-se pelo judicialismo (PRIETO SANCHÍS, 1997, p 108).

\section{DIMENSÕES DO ESTADO CONSTITUCIONAL}

No constitucionalismo contemporâneo, gerado a partir do segundo pós-Guerra obedecendo aquela definição de Matteucci que concebia o constitucionalismo como técnica específica de limitação do poder com finalidade de garantia - registra-se uma forte tendência a limitação do poder que se traduz em um reforço da dimensão garantista e do conseguinte controle jurisdicional da Constituição por parte dos juízes. O legicentrismo das Constituição oitocentistas estaria definitivamente superado, pois teríamos um novo momento histórico, marcado pelo pluralismo normativo que reclama a centralidade e a supremacia da Constituição.

Assim, o atual paradigma constitucionalista une a esta dimensão garantista, derivada da tradição americana, uma inequívoca função diretiva que consagra a Constituição como projeto coletivo de transformação social, incorporando um denso conteúdo substantivo que confere as Constituições contemporâneas uma forte dimensão material. Convergem, assim, os elementos distintivos das tradições francesa e norte-americana. Por outro lado, a dimensão diretiva ou normativa do texto constitucional como norma que pretende modelar uma nova realidade social mais justa, mediante a introdução na Constituição de cláusulas materiais ou de conteúdo através de normas de princípios ou normas programáticas ${ }^{10}$.

Uma das novidades mais relevantes do constitucionalismo do pós-guerra é a introdução de princípios e normas programáticas. O Estado Social de Direito supõe a R. Fac. Dir. UFG, v. 40, n.1, p. 32 - 53, jan./jun. 2016 
Alfonso de Julios-Campuzano e Valéria Ribas do Nascimento

ampliação do catálogo de direitos para aqueles que se convém denominar direitos econômicos, sociais e culturais, direitos que, inspirados pelo valor igualdade, comportam uma atuação positiva do Estado como direitos-prestações com a conquista de objetivos de caráter social que requerem do Estado o desenvolvimento de determinadas políticas.

Frequentemente, essa dimensão social do Estado que implica a incorporação de novos direitos se materializa nas Constituições, mediante normas programáticas, que contemplam fins de caráter social e estabelecem as linhas fundamentais de ação política que deve desenvolver o Estado em seu projeto de reforma da sociedade. É necessário advertir-se que, ainda que a linha de demarcação entre normas programáticas e princípios seja muito tênue, aquelas respondem a concretos objetivos de política social que se condensam em direitos prestacionais - que implicam, portanto, uma obrigação de fazer por parte do Estado para garantir determinados serviços ou tutelar situações concretas -, enquanto que os princípios expressam orientações axiológicas gerais que se relacionam a coerência interna do ordenamento $^{11}$.

Os princípios, diferentemente das normas programáticas, contém orientações gerais de caráter essencialmente axiológico que permitem resolver determinados conflitos e que indicam o caminho a seguir no desenvolvimento normativo do ordenamento jurídico ${ }^{12}$. Os princípios jurídicos não obedecem ao esquema das regras que determinam a conduta ou omissão devida na conjectura contemplada da mesma norma. Dada a configuração genérica e aberta dos princípios como orientações gerais, estes se apresentam como normas cuja aplicação precisa de uma ulterior concretização, pois as cláusulas gerais que expressam, não habilitam para uma imediata materialização da prescrição normativa. Os princípios, por conseguinte, possuem uma importante capacidade expansiva cujo alcance se estende a um amplo conjunto das normas que integram o ordenamento. A redação necessariamente genérica, aberta e indeterminada das normas de princípio remete a uma concretização que relacione o enunciado normativo com os casos específicos, trabalho que se efetua através da posterior elucidação legislativa com alcance normativo do princípio e a clarificação interpretativa realizada pelos juízes ${ }^{13}$. Junto às regras, que disciplinam analiticamente as relações entre os órgãos do Estado, os aspectos fundamentais de seu regime institucional, suas funções e competência, que integram principalmente a parte orgânica da Constituição, os princípios delimitam os conteúdos axiológicos da norma fundamental, os quais devem condicionar todas as normas do ordenamento. Suas orientações constituem, portanto, direções de conteúdo que indicam o caminho pelo qual o ordenamento deve transitar, desenvolvendo 


\section{POR QUEM DOBRAM OS SINOS? [...]}

especificamente os diversos âmbitos da vida social regulados pelo direito, o núcleo axiológico que representa os princípios, tais como o catálogo fundamental e valores como a liberdade, justiça, igualdade, solidariedade e a paz (ZAGREBELKY, 2006, pp. 34-35). O caráter essencialmente axiológico dos princípios indroduz, por consequência, um denso conteúdo substantivo na Constituição que permite falar, como afirmam alguns autores de remoralização do direito (ZAGREBELKY, 2006, pp. 37).

É evidente, que a presença deste tipo de normas programáticas e de princípios que ampliam o âmbito de eficácia da lei fundamental -, supõe uma transformação sem precedentes das características clássicas do constitucionalismo anterior, cujo paradigma, na opinião de certos doutrinadores, deve considerar-se superado. Para alguns autores, a plural tipologia normativa constitucional comporta, por outro lado, uma transformação paradigmativa que afeta as funções clássicas da Constituição e que se consubstancia na necessidade de uma política constitucional que permita transformar as normas que carecem de operatividade imediata em disposições jurídicas que concretizem os fins constitucionais, criando direitos e deveres. Aumentando a diferença entre as variadas normas constitucionais, Zagrebelsky pontualiza que, enquanto as normas organizativas dever ser conduzidas, as normas de princípio devem ser concretizadas, no mesmo sentido que as orientações políticas estabelecidas nas normas programáticas dever ser perseguidas (ZAGREBELSKY, 2007, p. 91).

Com a introdução dos princípios, o texto constitucional deixa de ser uma fonte, para se converter na norma suprema do ordenamento, cujos conteúdos substantivos centrados eminentemente em torno do catálogo de direitos fundamentais e a suas correlativas obrigações de ação ou de omissão -, cumprem a missão de dirigir normativamente o legislador, cuja atuação fica, por isso, condicionada. A validade das normas jurídicas depende, agora, não de uma vontade individual do legislador, submetida unicamente a exigências estritamente formais de competência e procedimento - quem manda e como manda - o próprio legislador pode modificar com facilidade, mas também com coerência efetiva, judicialmente determinada, os conteúdos da lei - que coisa se manda -, com os critérios substantivos de validação das normas jurídicas incorporadas à Constituição.

Por isso, as novas Constituições que se promulgam no pós-guerra incorporam complexos e intrincados procedimentos de reforma que cerceiam, definitivamente, aquela supremacia hábil e repulsiva da lei. O constitucionalismo contemporâneo, ao optar por modelos rígidos, está colocando o valor, o conteúdo material da Constituição e realçando sua 
Alfonso de Julios-Campuzano e Valéria Ribas do Nascimento

força normativa, que se apresenta agora como uma das prioridades do novo constitucionalismo. No fundo de todas estas transformações, registra-se uma distorção do modelo hierárquico desenhado pela teoria constitucional das fontes (PRIETO SANCHÍS, 2003, p. 121). A rigidez constitucional é a manifestação mais incontestável da vontade do constitucionalismo contemporâneo de fazer da Constituição a norma fundamental por excelência, reivindicando seu protagonismo, como verdadeira norma jurídica e ápice do ordenamento.

\section{A CONSTITUIÇÃO E O ORDENAMENTO JURÍDICO}

Nos dias atuais, a Constituição aparece concebida simultaneamente como sistema de garantias e como sistema de valores: deixou de ser um manifesto político para converter-se em uma verdadeira e precisa norma jurídica. E esta mutação, que supõe a consagração da Constituição como norma jurídica efetiva dotada de força normativa para modelar o conjunto do ordenamento, provoca a destruição do dogma estatalista da força absoluta da lei. A supremacia da Constituição vem colocar em quarentena a primazia da lei e a validade das normas jurídicas fica subordinada, agora, ao conteúdo substantivo encontrado na Constituição e na interpretação dos princípios constitucionais (FIORAVANTI, 2007, pp. 128-129). Como consequência, ao deslocar-se o centro de gravidade da produção normativa da lei - fonte primária de produção - à Constituição, como norma articuladora de uma multiforme e complexa variedade de normatividades, produz uma transformação substancial na configuração do ordenamento jurídico e na concepção de Direito que o acompanha.

O fim do primado da lei não é algo meramente verídico. Com o enfraquecimento desta premissa, caem, também, todo um complexo suporte de concepções e categorias que haviam sido criadas a sua sombra. Porque se a lei não é mais o elemento de referência, como se fará para medir, então, a adequação ao sistema jurídico? Como se poderá seguir buscando a aplicação meramente mecânica do texto legal? Eventualmente se poderá seguir refugiando-se na invocação dogmática de uma pretendida e inexistente mens legis? E o que dizer da validade das normas, da coerência e da racionalidade jurídica em um ordenamento fragmentado por uma multiplicidade normativa que quebra o paradigma epistemológico da dogmática jurídica tradicional $?^{14}$

Em suma, o deslocamento da lei para a Constituição é algo mais que um movimento estratégico. O sistema de subordinação que instaurou o princípio da legalidade R. Fac. Dir. UFG, v. 40, n.1, p. 32 - 53, jan./jun. 2016 


\section{POR QUEM DOBRAM OS SINOS? [...]}

precisou de todo um complexo teórico que deu suporte a ele, agora, como consequência do deslocamento do centro de gravidade dos ordenamentos democráticos, o mesmo perde sentido. Em um breve, mais interessante estudo intitulado Constitucionalismo e Positivismo, Prieto Sanchís indagou sobre estas e outras questões relacionadas com o modelo jurídico representado no Estado constitucional de Direito. A Constituição - sustenta o autor -

no ha venido simplemente a ocupar el papel de la ley, sino a diseñar un modelo de producción normativa notablemente más complejo, donde todos los sujetos encuentran no un orden jerárquico unívoco, sino orientaciones de sentido conflictivo que exigen ponderación (PRIETO SANCHÍS, 1997, pp. 35-36).

Como consequência, o complexo de transformações que estimula o surgimento do Estado constitucional aponta, no plano da produção normativa, para um processo de descentralização do protagonismo que a lei vinha exercendo entre as fontes do direito e, no plano da administração da justiça, a uma revalorização da função judicial que adquire um papel decisivo na determinação do conteúdo e alcance das cláusulas constitucionais. Simultaneamente, registram-se outras duas consequências: a primeira, no que concerne a interpretação e aplicação do direito; a segunda, no tocante a quebra do positivismo metodológico ou conceitual, pois este novo constitucionalismo professa um compromisso inevitável que se reflete no enfoque comprometido dos problemas que afetam a ciência jurídica ${ }^{15}$ (PRIETO SANCHÍS, 1997, p. 16).

Relacionando todos estes elementos aparece o que Massimo La Torre denominou de rematerialização dos documentos constitucionais e que vem expressar a ideia de que a Constituição configura uma ordem de valores ou uma unidade material que para alguns é prévia ao direito positivo (PRIETO SANCHÍS, 1997, pp. 16-17). Por essa via, a rematerialização constitucional garante que o bloco axiológico incorporado a Constituição exerça efetivamente uma função legitimadora das normas e decisões jurídicas. Daí que o caráter central da Constituição supõe uma transformação substancial na configuração do ordenamento e da própria Ciência do Direito, pois a incorporação deste núcleo substantivo de valores ao plano constitucional tem a virtude de estabelecer critérios efetivos de validade e legitimidade das normas jurídicas que vão muito além das exigências estritamente formais, formuladas pela dogmática jurídica ${ }^{16}$.

Nessa medida, a ordem jurídica, poderá assumir a carga valorativa do modelo do Estado constitucional a partir de uma nova óptica: a de um ordenamento jurídico que não se submete a Constituição, mas que a faz sua, na medida em que somente a congruência material R. Fac. Dir. UFG, v. 40, n.1, p. 32 - 53, jan./jun. 2016 
Alfonso de Julios-Campuzano e Valéria Ribas do Nascimento

de seus instrumentos normativos pode produzir para a mesma uma unidade sistemática. Se, durante décadas e inclusive séculos, a consistência teórica do direito dependeu da lógica de suas proposições normativas ou das condições intrassistemáticas que conferem validade as peças do ordenamento, hoje se pode afirmar que a nova argamassa do direito do século XXI será a congruência material dos conteúdos normativos: sua concordância substantiva com o conjunto de postulados que identificam as necessidades humanas, a presença de um forte conteúdo material da Constituição, que se irradia até todo o ordenamento jurídico ${ }^{17}$. O neconstitucionalismo possui um compromisso axiológico aberto e permeado por um conjunto de valores que marcam a direção da ordenação social, dos programas normativos, das ações políticas e das medidas legislativas.

\section{CONSIDERAÇÕES FINAIS: CONSTITUIÇÃO E LEGITIMIDADE}

Como indicou Ferrajoli, o modelo do Estado constitucional está associado a uma modificação substancial nas condições de existência e validade das normas jurídicas, pois a legalidade mesma fica, agora, subordinada a Constituição e garantida por uma específica jurisdição de legitimidade - a jurisdição constituiconal. A Constituição - e com ela seus conteúdos substantivos - é elevada a condição de norma de reconhecimento ou garantida de validade das normas. Desse modo, ao introduzir uma dimensão substancial nas condições de validade das normas, o constitucionalismo contemporâneo completa, na opinião de Ferrajoli, tanto o Estado de Direito como o próprio positivismo jurídico, na medida em que se incorporam as condições de validade das normas não somente o ser do direito, como também o dever ser (FERRAJOLI, 2005, p. 18 ss) ${ }^{18}$.

Desse modo, a operatividade da validade nos ordenamentos jurídicos contemporâneos se resolve num jogo de três bandas entre legitimidade, eficácia e validade, sendo esta última o recipiente estritamente normativo, no qual ficarão absorvidas as demandas essenciais da cidadania. Em definitivo, a dimensão axiológica do constitucionalismo contemporâneo constitui o elemento dirimente não somente da legitimidade, mas também da própria identidade do ordenamento jurídico enquanto tal, já que este fica profundamente impregnado dos valores constitucionais. A constitucionalização do ordenamento jurídico alcança, assim, de plano seus princípios essenciais:

a) A racionalidade do ordenamento jurídico está em relação diretamente proporcional a sua capacidade para perseguir fins previamente definidos que podem resultar R. Fac. Dir. UFG, v. 40, n.1, p. 32 - 53, jan./jun. 2016 


\section{POR QUEM DOBRAM OS SINOS? [...]}

compatíveis, o que implica um esforço por contemplar o texto constitucional não como um conjunto isolado de normas sem vinculação imediata entre elas, mas sim como um compacto bloco normativo, cuja interdependência imprime a ela vocação de totalidade. Vale, ainda, observar que devido à racionalidade tecnológica ou instrumental, cuja preponderância no âmbito científico-técnico provocou sua frequente alteração até a órbita jurídica, faze-se necessário reclamar uma racionalidade dos fins, uma racionalidade de caráter teleológico capaz de imprimir ordem na vida prática do homem.

b) Em segundo lugar, a unidade do ordenamento requer, ademais, um esforço inovador por integrar um conjunto de redes normativas transnacionais, em que o sistema constitucional - redimensionando alguns dos conceitos e instrumentos já clássicos de teoria do ordenamento jurídico - aceita um novo instrumental teórico, que não somente permite desenhar garantias frente à interferência nos âmbitos de validade das normas de diferentes procedências, mas também, encontra mecanismos constitucionais de alcance supranacional capazes de integrar os fluxos normativos transnacionais na dimensão axilógica constitucional. O pluralismo não é necessariamente um fenômeno negativo, antes disso, é uma realidade indiscutível que pode ter efeitos saudáveis na revitalização de certos espaços de cidadania e no aumento progressivo de responsabilidades por parte de certos setores da sociedade civil.

c) No que concerne a coerência, resulta manifesto que o futuro do direito como sistema interdependente de normas dotado de uma dose aceitável de compatibilidade significativa, exige nos dias atuais, algo substancialmente distinto das correntes lógicas de validade que genuinamente estiveram presentes durante décadas, por uma concepção lastreada de sistematicidade do ordenamento. De uma ou outra forma, a coerência constitui, certamente, uma das pedras angulares do ordenamento jurídico. E ninguém pode ocultar que, justamente por isso, é uma das características mais perseguidas pela avalanche normativa que se precipitou nestas últimas décadas, tanto em nível inter ou transnacional. Seja como for, as circunstâncias se alteraram tão drasticamente que, dificilmente, pode-se seguir sustentando aquela concepção clássica do ordenamento jurídico. Assim, parece lógico que, em boa medida, o conceito de coerência precisa ser profundamente reconsiderado para uma nova concepção, que busque a rematerialização constitucional, através da ponderação dos bens e valores constitucionais salvaguardados por uma contemplação global do bloco constitucional, que tende a suprimir as distâncias entre as concretas formulações normativas da norma suprema e a percepção social desse núcleo duro da Constituição não escrita, que constitui, sem dúvida alguma, o banco de provas da legitimidade constitucional. 
d) Finalmente, a crise do princípio da legitimidade demanda uma reconsideração profunda em duplo sentido, já parcialmente anunciado. Em primeiro lugar, porque a legitimidade não pode seguir sendo concebida como uma característica extrajurídica da norma, ao contrário, é preciso que fique associada a uma concepção dinâmica de validade, de sorte que esta seja a variável em termos sistemáticos das exigências de legitimidade e eficácia. Em segundo lugar, porque a legitimidade extrajurídica não pode seguir desvinculada da legitimidade política. O reconhecimento da autoridade legislativa é o ponto de partida que retira o processo psicológico do reconhecimento da legitimidade da norma, de sorte que toda legitimidade jurídica remete, em última instância, a uma legitimidade $a b$ origine de natureza política.

Assim, os políticos têm um compromisso inequívoco com a democracia que lhes atribui uma ação decisiva em âmbito supranacional, mediante a articulação de medidas efetivas de participação política (CAMPBELL, D; LEWIS, N. D., 1999). Existe uma conexão imediata entre constitucionalismo e participação política, pois a base de todo regime constitucional é a expressão da vontade cidadã através de procedimentos legalmente previstos, e a cidadania, enquanto centro de imputação de direitos e obrigações, somente adquire sentido em uma ordem democrática através do exercício efetivo de participação democrática (LEWIS, 1996, pp. 1-30).

O novo desenho institucional das relações internacionais na ordem global deve ficar sob o guarda-chuva protetor da legitimidade democrática. Difícil tarefa que requer um duplo compromisso: a) o desenvolvimento de uma estrutura institucional supraestatal dotada de mecanismos adequados de representação em condições de paridade; b) a abertura do cenário supranacional a novos atores transnacionais, cuja participação nos processos de tomada de decisões pode refletir as demandas, iniciativas e inquietudes de uma sociedade civil transnacional no status nascendi.

A argamassa do ordenamento jurídico do século XXI não é outra que a congruência material dos conteúdos normativos com o bloco axiológico que simboliza a norma suprema, ou melhor, a rematerialização da Constituição leva, desse modo, a rematerialização do ordenamento, um ordenamento cuja sobrevivência fica condicionada a superação dos velhos esquemas de validade já definitivamente ultrapassados. A ordem jurídica não subsiste a margem da realidade em que se desenvolve, não tem uma lógica própria nem goza de características distintivas de um sistema autopoiético, sua autonomia não é independente e, provavelmente seja, também uma autonomia em quarentena. 
Neste momento, é necessário que a ciência jurídica e a teoria do direito abram os olhos a realidade mutante e vertiginosa do mundo atual, assumindo definitivamente o compromisso moral e rotundamente jurídico de enfrentar os desafios dos novos tempos, auxiliando o rompimento com a racionalidade jurídica do velho modelo constitucional e buscando a reconciliação entre direito e justiça. Chegou o instante do constitucionalismo contemporâneo superar a matriz estatalista que lastreou a vigência efetiva de seus postulados.

Nos dias atuais, a congruência material de um constitucionalismo liberado definitivamente de arquetipos pseudocientíficos faz emergir sua própria vocação universalista. O constitucionalismo de amanhã, somente, existirá se romper definitivamente a matriz ultrapassada de uma ciência jurídica estreitamente formalista e o confinamento espacial de seus limites territoriais. A coerência do ordenamento constitucional convoca a uma ciência jurídica comprometida com os princípios constitucionais, uma ciência generalista capaz de transcender as fronteiras do velho estatalismo e articular mecanismos de cooperação capazes de modular um eficaz sistema de garantias para a tutela dos direitos. $\mathrm{O}$ futuro dos direitos, na era da interdependência, evoca assim um deslocamento das sedes do constitucionalismo, um reencontro com a validade e legitimidade no cenário da cooperação transnacional. O constitucionalismo de signo cosmopolita deixa de ser apenas uma utopia e passa a converterse na única brecha transitável para a salvaguarda efetiva dos direitos humanos.

\section{REFERÊNCIAS}

ARTOLA, Miguel. Constitucionalismo en la historia. Barcelona: Crítica, 2005.

CAMPBELL, D.; LEWIS, N. D. Promoting Participation: Law or Politics?, London: Cavendish, 1999.

COELHO, Luiz Fernando. Teoria Critica do Direito, 2 ed. Porto Alegre: Sergio Antonio Fabris, 1991.

DE ASÍS, Rafael. Una aproximación a los modelos de Estado de Derecho. Madrid: Dykinson, 1999.

DE VEGA, Pedro, "Apuntes para una historia de las doctrinas constitucionales del siglo XX". In: 〈http://www.bibliojuridica.org/libros/1/114/3.pdf>. Acesso em 24 de novembro de 2009.

FERRAJOLI, Luigi. Derechos y garantías. La ley del más débil; traducción de Perfecto Andrés Ibáñez. 5. ed. Madrid: Editorial Trotta, 2006.

.Garantismo. Una discusión sobre derecho y democracia, Trotta: Madrid, 2006.

R. Fac. Dir. UFG, v. 40, n.1, p. 32 - 53, jan./jun. 2016

ISSN 0101-7187 
.Pasado y futuro del Estado de derecho. In: CARBONELL, Miguel (Org). Neoconstitucionalismo(s). Madrid: Editorial Trotta, 2005, p. 13-29.

FIORAVANTI, Maurizio. Los derechos fundamentales; apuntes de historia de las constituciones. Madrid: Trotta, 2007.

GOMES CANOTILHO, José Joaquim. Teoría de la Constitución. Dykinson: Universidad Carlos III, Madrid, 2004.

50 GUASTINI, Riccardo. Distinguiendo. Estudios de teoría y metateoría del derecho. Barcelona: Gedisa, 1999.

JIMÉNEZ ASENSIO, Rafael, El constitucionalismo. Proceso de formación y fundamentos del derecho constitucional, 3 ed. Marcial Pons, Madrid, 2005.

LEWIS, Norman D. The constitutional implications of participation. In: AA.VV. Promoting Participation: Law or Politics?. London; Sydney: Cavendish, 1999.

MATTEUCCI, Nicola. Organización de poder y libertad. Madrid: Trotta, 1998.

McILWAIN, Charles Howard. Constitucionalismo antiguo y moderno. Madrid: Centro de Estudios Constitucionales, 1991.

PECES-BARBA, Gregorio. Epílogo Desacuerdos y acuerdos con una obra importante. In: ZAGREBELSKY, Gustavo, El derecho dúctil. Ley, derechos, justicia. Madrid: Trotta, 1995.

Socialismo y libertad. In: Libertad. Poder. Socialismo. Madrid: Civitas, 1978.

PRIETO SANCHÍS, Luis. Constitucionalismo y positivismo. México: Fontamara, 1997.

Justicia constitucional y derechos fundamentales. Madrid: Trotta, 2003.

. Neoconstitucionalismo y ponderación judicial. In: CARBONELL, Miguel (Org). Neoconstitucionalismo(s), 2 ed., Trotta: Madrid, 2005, pp. 123-159.

REBUFFA, Giorgio, Costituzioni e Costituzionalismi. Torino: G. Gioppichilli, 1990.

TARELlO, Giovanni. Cultura jurídica y política del derecho. México: Fondo de Cultura Económica (etc.), 1995.

ZAGREBELSKY, Gustavo. Fragilità e forza dello Stato costituzionale. Napoli: Editoriale Scientifica, 2006.

.La Constitución y sus normas. In: CARNOELL, Miguel (Org.). Teoría del neoconstitucionalismo. Ensayos escogidos. Madrid: Trotta, 2007.

\footnotetext{
${ }^{1}$ Ressalta-se o título original do texto: ¿POR QUIÉN DOBLAN LAS CAMPANAS? Vale pontuar que os verbos da língua espanhola "doblar" e "tocar" possuem o mesmo significado, mas introduzem matizes com algumas diferenciações. Em espanhol, os sinos "doblan" somente pelos mortos, quer dizer um tipo de toque particular, de luto.
}

R. Fac. Dir. UFG, v. 40, n.1, p. 32 - 53, jan./jun. 2016 
2 Assim, consuma-se o que Peces-Barba denominou "la presentación farisaica del viejo pensamiento liberal revolucionario", convertido ya en "cínica representación de los desnudos intereses de la burguesía" y en "liberalismo instalado y decadente" PECES-BARBA, Gregorio, 1978, p. 148).

${ }^{3}$ Para Coelho, os pressupostos ideológicos do positivismo legalista e da dogmática jurídica são os da unicidade o direito é somente um; não existe outro direito que não o direito positivo -; estatalidade - o único direito positivo é o promulgado pelo Estado - e racionalidade - o direito é objetivamente racional já que, enquanto produto de uma elaboração científica, concretiza-se em uma estrutura analítica objetiva cuja racionalidade é imanente, independentemente de quais sejam seus conteúdos - que constituem um tripé ideológico sobre o que sustenta um quarto princípio, o da legitimidade. Segundo este, o direito é considerado legítimo não em função de algum fator metajurídico, mas sim simplesmente porque é um único direito, estatal e racional. Esta concepção, nas palavras de Coelho, resulta em uma tautologia: o direito é legítimo porque é o direito e o direito é o direito porque é legítimo (COELHO, Luiz, Fernando, 1991, Capítulo IX, epígrafe IV).

${ }^{4}$ Desse modo, a Constituição encontra dificuldades insuperáveis para sua materialização no ordenamento jurídico, já que sua força normativa está profundamente condicionada pelo poder supremo do legislador, que personifica a rousseauniana vontade geral que é, por si mesma, ilimitada. Esta idéia do poder constituinte que não quer se esgotar nos estreitos confins de um documento jurídico, faz com que o constitucionalismo se transforme em legalismo, ao atribuir ao poder político de cada momento a faculdade de realizar ou de frustar o que se reuniu na Constituição (PRIETO SANCHÍS, Luis, 2003, pp. 108-109).

${ }^{5}$ Este conceito de nação é, desde o início, um conceito ideológico, de caráter restritivo que representa uma marca inequivocadamente combativa. O conceito de nação implica a existência de um inimigo que se tem de vencer: a categoria dos privilegiados. Por nação deve-se identificar, portanto, ao povo, aos amigos da revolução, situação que, afirmada já desde o início da Revolução, ver-se-ia transformada, na fase jacobina, com a ampliação desmedida dos inimigos do povo, dando lugar a fase do Terror (FIORAVANTI, 2007, pp. 63-64).

${ }^{6}$ Não obstante, esse abandono dos processos de reforma, que constitui uma proverbial causalidade do constitucionalismo inspirado no modelo pós-revolucionário francês concentra sua mais destacada expressão na Constituição francesa de 1791, na qual se contemplaram mecanismos que puderam frear as vontades reformadoras de eventuais maiorias. Para isso, estabelecia-se como condição para a reforma, que três legislaturas coincidissem na necessidade de modificação, a qual seria efetuada mediante uma assembléia de revisão composta pelo legislativo e 249 membros. As Constituições posteriores, no entanto, deixaram de adotar esse tipo de precauções (ARTOLA, Miguel, 2005, p. 7).

${ }^{7}$ Assinala, Prieto Sanchís, que a primazia da lei supõe a permanência de um poder constituinte continuamente operante, símbolo do poder legislativo, o qual representa a ilimitada vontade geral rousseauniana. Esta situação dificultou muito a estabilidade dos textos constitucionais que encontraram graves obstáculos para manter sua força normativa frente aos poderes constituídos; por isso, o constitucionalismo transformou-se em legalismo, atribuindo-se ao poder político de cada momento o poder de dispor, em seu mais amplo sentido, sobre o grau de cumprimento efetivo das cláusulas constitucionais (PRIETO SANCHÍS, Luis, 2003, p. 109).

${ }^{8}$ Em resumidas notas, para o constitucionalista italiano, se puede afirmar que la revolución francesa confía los derechos y libertades a la obra de un legislador virtuoso, que es tal porque es altamente representativo del pueblo o nación, más allá de las facciones o de los intereses particulares; mientras que la revolución americana desconfía de las virtudes de todo legislador -también del elegido democráticamente...- y, así, confía los derechos y libertades a la Constitución, es decir, a la posibilidad de limitar al legislador con una norma de orden superior, p. 83 (FIORAVANTI, Maurizio, 2007, pp. 78 ss.; Sobre este mesmo aspecto do constitucionalismo americano, consultar Giorgio Refubba (REBUFFA, Giorgio, 1990, pp. 47 ss)..

${ }^{9}$ Para uma entender a evolução histórica do constitucionalismo, cita-se Charles Howard McILWAIN; Nicola Matteucci; Miguel Artola; etc. (McILWAIN, 1991; MATTEUCCI, 1998; ARTOLA, 2005).

${ }^{10}$ Sobre esta dupla dimensão do constitucionalismo contemporâneo como norma fundamental de garantia e como norma diretiva fundamental, consultar: Maurizio Fioravanti (FIORANTI, 2007, pp. 127 ss) e Luis Prieto Sanchís (PRIETO SANCHÍS, 2005, pp. 125 ss) que concebem a Constituição contemporânea como Constituição normativa garantida.

11 Para Zagrebelsky a reiterada opinião doutrinária que enfatiza o escasso valor das normas programáticas, enfraquecendo seu caráter normativo até convertê-lo em meramente testemunhal, constitui uma simplificação carente de fundamento. $\mathrm{O}$ ponto de vista de quem questiona a condição constitucional das normas programáticas, reduzindo-as ao caráter de medidas ou programas políticos alheios, portanto, a Constituição é unilateral. Considerando-se que as normas jurídicas não servem exclusivamente para criar posições jurídicas perfeitas; isto é, direitos e deveres, mas sim que cabe a elas, também, desempenhar a função de meios para acelerar o processo político, ampliando as bases de consenso e participação. As normas programáticas, em sua opinião, contribuem para se estabelecer os limites do debate político, a definir os parâmetros de ação do governo e a concretizar os objetivos sociais que devem ser perseguidos. Nesse sentido, as normas programáticas retiram decisões do âmbito político e sujeitam a ação política a um marco social previamente determinado nas normas constitucionais de 
programa que indica a direção e o projeto social que o legislador deve levar a cabo. Essa é a virtude das normas programáticas: reduzir o espaço de controvérsia com caráter prévio ao debate político e criar uma direção genérica, que será posteriormente concretizada em ações legislativas e de governo em torno do qual o projeto político deve orientar-se. Por isso, as normas programáticas, insiste o jurista italiano, não são substancialmente diferentes de outras normas constitucionais. $\mathrm{O}$ fato de que se dirigem ao legislador e que requerem decisões concretas para alcançar os fins constitucionais não permite concluir nada em relação à sua qualidade normativa. A redução do debate político que delas deriva somente significa uma diferença de grau, não de função (ZAGREBELSKY, Gustavo, 2007, p. 87).

${ }^{12}$ Sobre a caracterização, acepções e alcance dos princípios jurídicos em geral, ver: GUASTINI, Riccardo. Los principios en el derecho positivo (GUASTINI, Riccardo, 1999, pp. 142-178).

13 A estrutural capacidade expansiva dos princípios, cujos limites - a diferença das regras - não estão especificados com exatidão, determina que, com frequência, surjam conflitos entre princípios diferentes, que devem ser resolvidos mediante o juízo de ponderação pelos juízes, na solução de cada caso; igualmente, cabe ao juiz definir, eventualmente, o grau de satisfação de um princípio concreto, conforme as exigências da Constituição. Esta situação alterou substancialmente a função dos juízes, redimensionando a importância da interpretação, que já não pode ser reduzida a concepção lógico-dedutiva preconizada pelo positivismo legalista, porque não existe uma solução aplicável com caráter definitivo; mas sim, é o intérprete que deve construir uma solução para cada caso concreto, mediante uma analise das circunstâncias do fato e da realidade social a que o conflito se refere. Isso converte a interpretação em atividade inesgotável, como assevera Zagrebelsky, "el punto de equilibrio se muestra siempre históricamente contingente" (p. 86); sobre as características do juízo de ponderação (ZAGREBELSKY, Gustavo, 2007, pp. 83 ss). Consultar ainda Luis Prieto Sanchís (PRIETO SANCHÍS, 2003, pp. 175-216).

${ }^{14}$ A crise do modelo constitucional vem alimentada, como aponta Gomes Canotilho, por uma crise na teoria da Constituição que se percebe esgotada desde cima, pelas teorias filosóficas da justiça, e, por baixo, pelas teorias sociológicas do direito As primeiras aproveitaram a crise da teoria constitucional para redesenhar em termos contratuais os modelos de sociedade bem ordenada. As segundas, acentuam a tensão entre a realidade sociológica e o idealismo indestrutível da teoria constitucional, enfrentando dramaticamente as exigências de faticidade e validade, tensão que ameaça dissolver a própria teoria constitucional. Desse modo, põe-se de manifesto a impossibilidade da teoria constitucional contemporânea para se instalar o que Gomes Canotilho denomina da situação clássica, isto é, aquela em que existe um acordo estável acerca de categorias jurídicas, aspectos conceituais e métodos de conhecimento (GOMES CANOTILHO, José Joaquim, 2004, pp. 1-36).

${ }^{15}$ Sobre a compatibilidade do positivismo com a inclusão de conteúdos de justiça ou legitimidade no Estado de Direito, cita-se a posição de Rafael De Asís (DE ASÍS, Rafael, 1999, pp. 145 ss), em que o autor sustenta uma posição que contrasta com pronunciamentos de um setor importante da doutrina que rebate essa compatibilidade. A posição de De Asís está de acordo também com as críticas que Peces-Barba formula sobre este ponto a tese de Zagrebelsky. Em sua crítica ao jurista italiano, o professor da Universidade Carlos II opõe-se a valoração daquele, sobre a quebra do positivismo no constitucionalismo contemporâneo e sua incapacidade para abordar e interpretar as novas direções da cultura jurídica (PECES-BARBA, Gregório, 1995, pp.157-173).

16 Ao explicar este desenvolvimento Prieto Sanchís remete-se a posição de Ferrajoli que destaca ter o constitucionalismo moderno incorporado gran parte de los contenidos o valores de justicia elaborados por el iusnaturalismo racionalista e ilustrado". Desse modo, produz-se uma aproximação "entre la legitimación interna o deber ser jurídico y legitimación externa o deber ser extrajurídico. Daí, continua Prieto, ressaltando as transcendentais consequências que este fenômeno tem para o modelo de Estado de Direito Legislativo: el legislador ya no es la viva voz del soberano, legitimado para dictar normas con cualquier contenido, sino que, sin convertirse tampoco en un autómata ejecutor de la Constitución, ha de acomodar su política a las amplísimas (también ambiguas y contradictorias) exigencias constitucionales (PRIETO SANCHÍS, Luis, 1997, p.17).

${ }^{17}$ É o fenômeno do alargamento da Constituição associado a rematerialização da norma constitucional e a sua garantia jurisdicional efetiva. Produz-se, assim, uma imersão da Constituição no conjunto do ordenamento jurídico, que deixa de precisar da mediação do legislador. O acesso a Constituição como norma suprema deixa de estar mediado pela lei - que fica desvalorizada e depreciada pela força normativa da Constituição, do bloco axiológico que se proclama através dos princípios - para ficar agora livre desse condicionamento. Ao desaparecer o monopólio do legislador sobre a Constituição, esta deixa de estar aprisionada e adquire plena vigência social, como conjunto normativo acessível de modo permanente, que regula a ampla variedade dos fenômenos sociais, os quais confere a Constituição um principal protagonismo, pois não há problema jurídico que não tenha relevância constitucional. (PRIETO SANCHÍS, Luis, 2005, p. 130 ss). Guastini refere-se a isso, como a constitucionalização do ordenamento jurídico, fenômeno que tem sua causa na combinação de uma multiplicidade de fatores que rompe os velhos esquemas da dogmática jurídica e que se conecta com a concepção da Constituição como um texto aberto do ordenamento (GUASTINI, Riccardo,2005, pp. 49 ss).

R. Fac. Dir. UFG, v. 40, n.1, p. 32 - 53, jan./jun. 2016

ISSN 0101-7187 
${ }^{18}$ Sobre a incorporação ao texto constitucional do dever ser e sua incidência na configuração das duas dimensões de validade e suas consequências sobre o paradigma constitucional (FERRAJOLI, 2005; FERRAJOLI, 2006). Em sua obra Derechos y garantías. La ley del más débil, o doutrinador realiza uma ampla análise das transformações da validade no constitucionalismo contemporâneo, que passou de identificar-se com a mera existência das normas, para admitir em seu seio uma dimensão material, vinculada agora aos conteúdos substanciais refletidos na Constituição. Partindo dessas premissas, o autor italiano distingue entre a vigência, referida a forma dos atos normativos, quer dizer, a sua correspondência com as exigências formais previstas nas normas sobre sua produção; e a validade, que concerne ao significado e que, portanto, é uma consequiência da coerência ou compatibilidade das normas de produção com aquelas outras que estabelecem prescrições de caráter substancial sobre a produção daquelas (FERRAJOLI, 2006, pp. 20-22).

Artigo recebido em 15 de abril de 2015 e aceito em 20 de outubro de 2015 